\title{
Characterization of the vascular changes in schistosomal portal (pipestem) fibrosis of mice
}

\author{
Luciana M. Silva ${ }^{\text {a }}$, Ricardo Ribeiro-dos-Santos ${ }^{\mathrm{b}}$, \\ Milena B.P. Soares ${ }^{b}$, Zilton A. Andrade ${ }^{\mathrm{a}, *}$ \\ a Laboratories of Experimental Pathology, Gonçalo Moniz Research Center/FIOCRUZ, Salvador, BA, Brazil \\ b Tissue Engineering and Immunopharmacology, Gonçalo Moniz Research Center/FIOCRUZ, Salvador, BA, Brazil
}

Received 25 August 2005; received in revised form 20 January 2006; accepted 20 January 2006

Available online 14 March 2006

\begin{abstract}
Mice chronically infected with Schistosoma mansoni develop one of two anatomical forms of hepatic lesions: severe, periportal (pipestem) fibrosis or milder, isolated granulomas. The pathogenesis of periportal fibrosis is poorly understood. In this work we compared mice with either periportal fibrosis or isolated granulomas to identify specific markers of severe pathology. BALB/c or Swiss Webster mice were infected with 30 cercarie, once or six times, and liver biopsies were performed to classify the animals into two pathological groups 16 weeks later. Sixty percent of the animals sacrificed at 20 or 24 weeks had periportal fibrosis, 15-20\% had isolated granulomas and the remainder had indeterminate pathology. There was no correlation between frequency of infections or egg burden (eggs/g liver) at 20 and 24 weeks post-infection and the development of periportal fibrosis. Livers with periportal fibrosis at 20 or 24 weeks of infection were characterized by larger areas of fibrotic tissue and greater vascularization compared to livers of mice with isolated granulomas. Plastic casts of the portal vein system showed marked changes in vascular structure in mice with periportal fibrosis, including collateral vessels sprouting from the main portal branches, amputation of the more delicate peripheral ramifications, and distortions of the medium and small branches. Vascular changes were not observed in mice with isolated granulomas. These results suggest that the interaction between schistosome eggs and portal vascular changes is of paramount importance in the development of pipestem fibrosis.
\end{abstract}

() 2006 Elsevier B.V. All rights reserved.

Keywords: Schistosoma mansoni; Periportal (pipestem) fibrosis; Periovular granulomas; Hepatic fibrosis

\section{Introduction}

Despite the description a century ago of the characteristic "pipestem" lesion by Symmers (1904) the pathogenesis of schistosomal periportal fibrosis remains

\footnotetext{
* Corresponding author at: Laboratório de Patologia Experimental, Centro de Pesquisas Gonçalo Moniz/FIOCRUZ, Rua Waldemar Falcão, 121-Brotas, Salvador 40295-001, BA, Brazil.

Tel.: +55 $713564320 \times 266$; fax: +55 713562155 .

E-mail address: zilton@cpqgm.fiocruz.br (Z.A. Andrade).
}

controversial. It is recognized that the lesion appears in heavily infected individuals and represents the morphological substratum of hepatosplenic schistosomiasis. However, not all heavily infected individuals living in an endemic area will necessarily develop hepatosplenic disease. The influence of several factors, such as host age and gender, genetic background, nutrition, immunological status, and environmental factors have been discussed (Prata, 1991), but evidence for their specific roles in pathogenesis is incomplete. There is no explanation for the finding that the majority of infected individuals 
present with isolated periovular granulomas in their livers, while only a few develop dense fibrous periportal plaques. Furthermore, it is not known why infected people who emigrate from an endemic area rarely develop pipestem fibrosis. If transmission is interrupted from an endemic area, severe manifestations of schistosomiasis, including hepatosplenic disease, tend to subside, which points to the influence of reinfection in pathogenesis (Bina and Prata, 1984).

As happens in human patients, S. mansoni infection of mice may evolve to one of two forms of disease: a mild or hepato-intestinal form, characterized by the presence of scattered periovular granulomas in the liver parenchyma; and a severe, hepatosplenic form with concentration of periovular granulomas in periportal spaces, resulting in periportal fibrosis. A small percentage of mice with prolonged infection (16 weeks) and relatively low worm burden (1-2 pairs of worms) develop periportal fibrosis, characterized by a concentration of periovular granulomas in periportal spaces (Warren, 1966). Andrade (1987) demonstrated that the presence of eggs into the dilated portal capillaries and veins preceded the periportal concentration of granulomas and fibrosis, indicating that vascular changes preceded development of periportal fibrosis. However, periportal fibrosis did not develop in all chronically infected mice, even when inbred mice were used (Andrade and Cheever, 1993), suggesting that other factors besides worm burden, duration of infection and genetic background are involved.

To investigate immunological and pathological markers of severe disease, we studied groups of mice that are exquisitely susceptible to periportal fibrosis. Immunological aspects related to periportal fibrosis have been described separately (Silva et al., 2004). Here, we compared pathological features of periportal fibrosis or isolated granulomas in mice, with special attention to changes in hepatic vasculature.

\section{Materials and methods}

\subsection{Animals and infection}

Male BALB/c and Swiss Webster mice weighing 15-20g were infected transcutaneously with approximately $30 \mathrm{~S}$. mansoni cercariae of the Feira de Santana strain (Andrade and Sadigursky, 1985). The cercariae were obtained from laboratory-raised and infected Biomphalaria glabrata. All animals for each experiment were infected on the same day with the same preparation of cercariae. A group of infected animals was submitted to repeated infection with 15 cercariae at each of five additional time points, at 15 day intervals, for a total of six infections. By the 16th week following the first infection, BALB/c mice were submitted to a surgical liver biopsy to classify the pathology as periportal fibrosis, scattered granulomas or mixed. Fragments of the liver, weighing approximately $100 \mathrm{mg}$, were fixed in Bouin's fluid and embedded in paraffin for sectioning. Sections were stained with hematoxylin and eosin or picro-siriusred for collagen (Junqueira et al., 1979).

\subsection{Experimental groups}

Based on the results of liver biopsy, the animals were segregated into three groups: (1) mice presenting schistosomal periportal fibrosis following single infection (PF/SI); (2) mice presenting scattered granulomas following single infection (SG/SI); (3) mice presenting periportal fibrosis following repeated infections ( $\mathrm{PF} / \mathrm{RI})$. Animals with an intermediate histologic picture, with features of both periportal fibrosis and isolated granulomas (mixed forms) were excluded from subsequent analysis.

\subsection{Evaluation of egg load, histology and collagen content in the liver}

Infected BALB/c mice were euthanized 20 and 24 weeks after the first cercarial exposure. Liver fragments were prepared as above, and stained with hematoxylin and eosin, picro-sirius-red, or orcein for visualization of elastin fibers. Worms were recovered using the Duvall and Dewitt (1967) perfusion method. Egg isolation, quantification, and calculation of the number of eggs per gram of liver were done according to Cheever (1970). Collagen content was estimated using hydroxyproline content, according to method B of Bergman and Loxley (1963).

\subsection{Immunofluorescence}

Liver fragments were placed in small carton boxes filled with Tissue-Tek (Milles, Torrance, CA, USA) and immediately frozen in liquid nitrogen for $5 \mathrm{~min}$. Blocks were then kept in air-tight plastic bottles at $-70^{\circ} \mathrm{C}$ until sectioned in a cryostat at $-20^{\circ} \mathrm{C}$. The sections were immediately fixed in cold acetone, washed in saline and treated with one of the following antisera: rabbit antihuman collagen I or rabbit anti-human laminin (kindly supplied by Dr. Jean-Alexis Grimaud, Institute Pasteur, Lyon, France). Primary antisera were diluted 1:20 or 1:50 in PBS. The secondary antibody was a fluoresceinconjugate anti-rabbit IgG (Sigma, St. Louis, MO, USA), diluted 1:20 in PBS contained Evans blue (0.05\%). Con- 
trol sections were incubated with saline only or with normal rabbit serum.

\subsection{Automated morphometry}

Microscopy fields were randomly selected and a total area of $12 \mathrm{~mm}^{2}$ on liver sections was analyzed for four animals of each group. All periovular granulomas with viable eggs were included. A spherical shape and normal size distribution were assumed. The percentage of fibrosis was calculated as the area stained with picrosirius-red divided by the total area examined. Similarly, the percentage of collagen or laminin was calculated as the percentage of fluorescence in the total area examined. For all automated morphometry, we used a color digital video camera attached to an Olympus AX-70 microscope with a $20 \times$ objective. The images were analyzed using the Image Pro Program (Media Cybernetics, Carlsbad, CA).

\subsection{Vascular injections}

Infected Swiss Webster mice were biopsied 16 weeks after infection and characterized as having periportal fibrosis or isolated granulomas. Uninfected mice were used as controls. The animals were first intraperitoneally injected with $200 \mu \mathrm{l}$ of heparin. A $7 \%$ sodium citrate solution was flushed through the portal system to clear blood from it. This was immediately followed by injection of $14 \%$ solution of vinyl chloride-acetate in acetone (Grade VYHH, Union Carbide Plastics Co., USA), by applying positive pressure in $10 \mathrm{cc}$ syringe, until uniform filling of the portal veins was achieved. After injection, the liver was removed and kept in water overnight at $4{ }^{\circ} \mathrm{C}$. The liver tissue was digested in $50 \%$ hydrochloric acid solution for $48 \mathrm{~h}$. The plastic cast was washed several times in water and alcohol, dried, and examined directly under a dissecting microscope. The plastic casts were analyzed using a SZX-9 Olympus stereoscopic microscope coupled to a DP-12 Olympus digital camera.

\subsection{Statistical analysis}

Numbers of eggs, hydroxyproline content and morphometric data were analyzed using parametric or nonparametric methods. We used ANOVA to compare mean values for normally distributed data and Mann-Whitney (for two groups) or Wilcoxon (for three groups) tests to compare median values for non-normally distributed data.

\section{Results}

\subsection{Histopathological analysis and worm burden}

Periportal fibrosis was the principal pathologic presentation among mice surviving until 16 weeks after primary infection, whether mice were submitted to single or repeated infections (Table 1). Fig. 1A-C shows the main histological criteria used for classifying isolated granulomas and periportal fibrosis. Liver sections from mice with periportal fibrosis were characterized by a concentration of periovular granulomas in the periportal spaces, and variable amounts of intergranulomatous deposition of collagen forming the periportal lesion (Fig. 2A and C). Mice with periportal fibrosis following single or repeated infections and those with isolated granulomas showed no significant difference in hydroxyproline concentration in liver tissue, an indicator of collagen content (Table 2). However, total area of fibrotic tissue, as measured on picro-sirius stained sections with automated morphometry, was greater in livers from mice with periportal fibrosis compared to those with isolated granulomas (Fig. 3).

Recovery of worms by portal vein perfusion at the 20th week following cercarial exposition revealed that mice that developed periportal fibrosis following repeated infection $(\mathrm{PF} / \mathrm{RI})$ had a higher mean number of worms (21.0) than mice submitted to a single infection with periportal fibrosis (PF/SI 9.0; $p=0.02$ ). However, numbers of eggs were highly variable in individual mice, with no significant differences between groups at 20 and 24 weeks (Table 3).

Table 1

Classification of histopathological patterns as observed in biopsy material taken from BALB/c mice chronically infected with Schistosoma mansoni obtained 16 weeks after infection

\begin{tabular}{llllll}
\hline Duration of infection & Type of infection & Number of animals & Periportal fibrosis & Isolated granulomas & Indeterminate (mixed) \\
\hline Exp. 1, 20 weeks & Single & 63 & $37(59 \%)$ & $10(16 \%)$ & $16(25 \%)$ \\
& Repeated & 60 & $36(60 \%)$ & $4(7 \%)$ & $20(33 \%)$ \\
Exp. 2, 24 weeks & Single & 30 & $20(67 \%)$ & $6(20 \%)$ & $4(13 \%)$ \\
& Repeated & 10 & $5(50 \%)$ & $4(40 \%)$ & $1(10 \%)$ \\
\hline
\end{tabular}



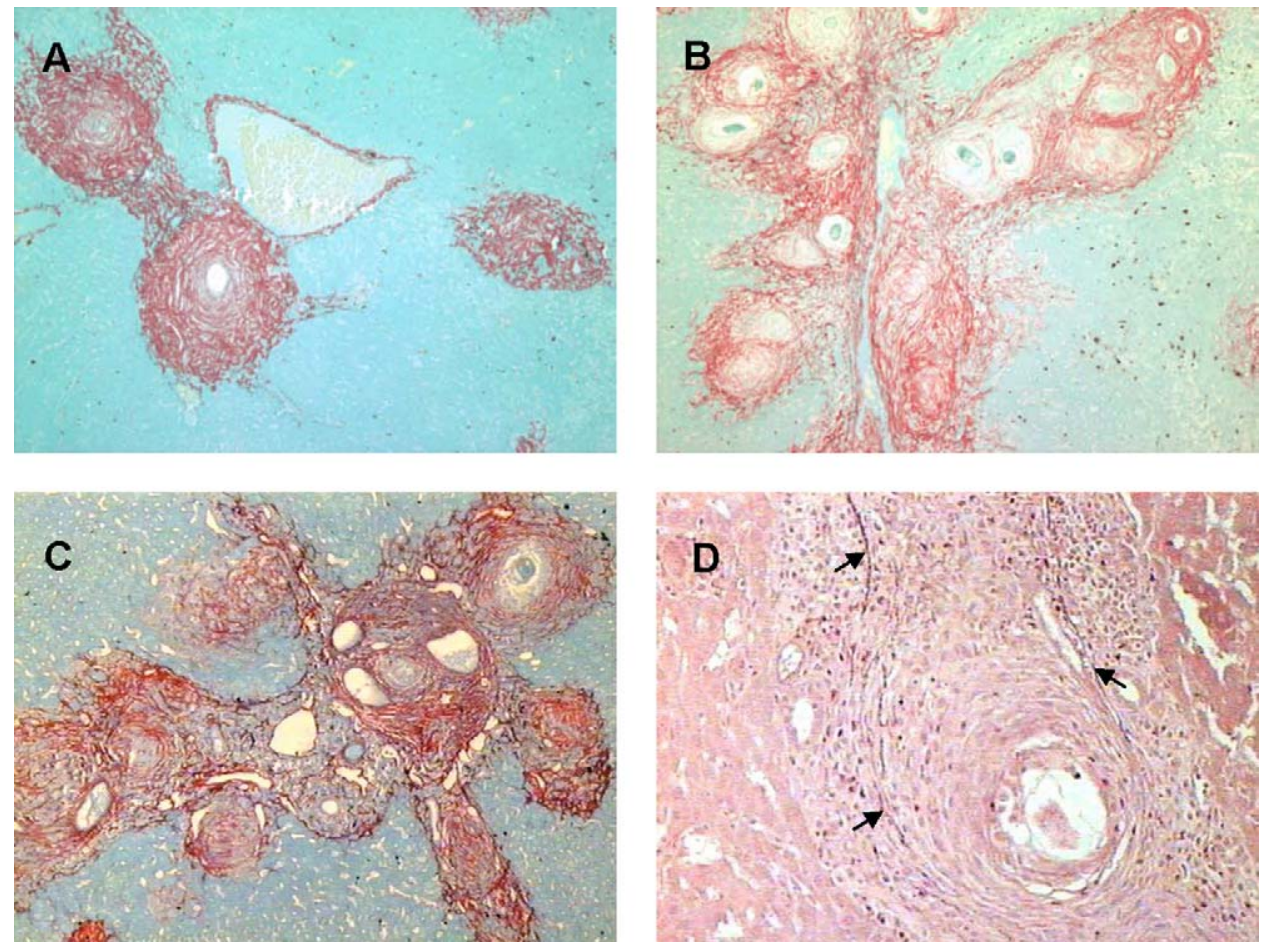

Fig. 1. Liver sections of S. mansoni-infected mice by optical microscopy. (A) Isolated periovular granulomas in the mouse liver. Picro-sirius-red, $100 \times$. (B and C) Schistosomal periportal fibrosis. Portal spaces are enlarged, and connected one to the other, by extensive fibrosis. Picro-sirius-red, $100 \times$. (D) Fine dark lines delineated the remains of a portal vessel, exhibiting a periovular granuloma in its interior. Mouse with periportal fibrosis. Orcein stain for elastin tissue, $200 \times$. Arrows indicate elastin fibers.

\subsection{Vascular changes}

Vascularization of isolated granulomas was markedly different from that of periportal fibrosis. Isolated periovular granulomas appeared in immunofluorescence as avascular structures, with only an inconspicuous corona of blood vessels at the periphery. Periportal fibrosis appeared as a richly vascularized fibrous tissue. Orceinpositive elastin fibers demarcated the wall of numerous vessels. In mice with periportal fibrosis, we observed occasional periovular granulomas with an intravascular location (Fig. 1D). Prominent vasculature was revealed

Table 2

Quantification of liver collagen by hydroxyproline determination

\begin{tabular}{lclc}
\hline Duration of infection & $\begin{array}{l}\text { Periportal fibrosis, repeated infections } \\
(\mu \text { mol hydroxyproline/g liver) }\end{array}$ & $\begin{array}{l}\text { Periportal fibrosis, single infection } \\
(\mu \text { mol hydroxyproline/g liver })\end{array}$ & $\begin{array}{l}\text { Isolated granulomas, single infection } \\
(\mu \text { mol hydroxyproline/g liver) }\end{array}$ \\
\hline Exp. 1, 20 weeks & $9.25 \pm 3.0$ & $14.24 \pm 7.64$ & $12.0 \pm 5.0$ \\
Exp. 2, 24 weeks & $11.21 \pm 1.65$ & $13.07 \pm 3.73$ & $14.25 \pm 3.45$ \\
\hline
\end{tabular}

Liver fragments of BALB/c mice were obtained 20 or 24 weeks after infection. Values represent the means \pm S.D. of hydroxyproline levels per gram of liver of six mice per group.

Table 3

Estimates of the number of Schistosoma mansoni eggs per gram of liver tissue, according to type and duration of infection, in correlation with the anatomical lesions

\begin{tabular}{lllc}
\hline Duration of infection & $\begin{array}{l}\text { Periportal fibrosis, repeated infections } \\
\text { (number of eggs/g liver) }\end{array}$ & $\begin{array}{l}\text { Periportal fibrosis, single infection } \\
\text { (number of eggs/g liver) }\end{array}$ & $\begin{array}{l}\text { Isolated granulomas, single infection } \\
\text { (number of eggs/g liver) }\end{array}$ \\
\hline Exp. 1, 20 weeks & $30.500 \pm 9.177$ & $17.380 \pm 4.851$ & $19.680 \pm 6.127$ \\
Exp. 2, 24 weeks & $10.450 \pm 7.779$ & $11.070 \pm 10.100$ & $4.795 \pm 2.623$ \\
\hline
\end{tabular}

Values represent the means \pm S.D. of number of eggs per gram of liver of six mice per group. 

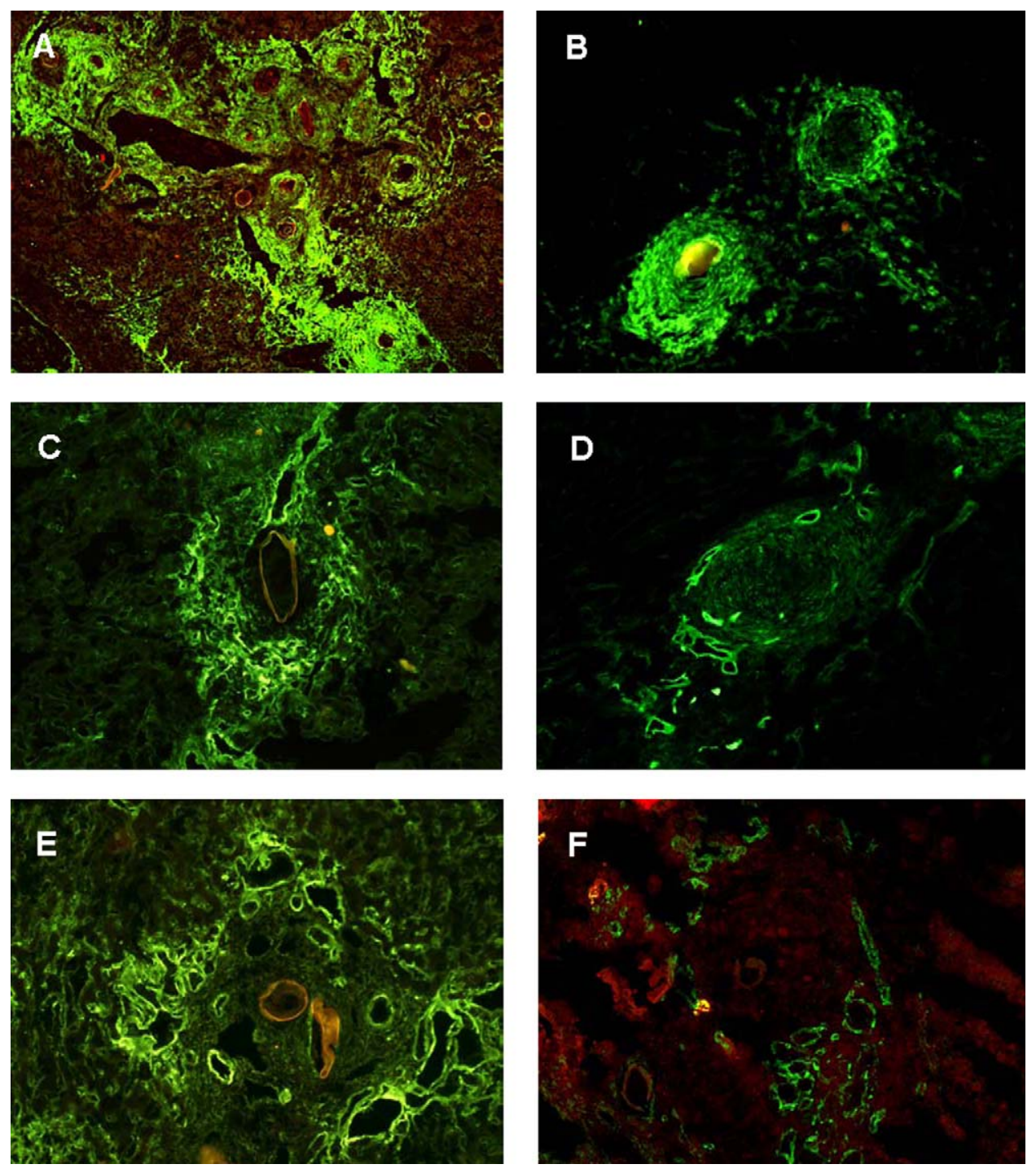

Fig. 2. Confocal microscopy of indirect immunofluorescence showing aspects of schistosomal granulomatous lesions in the liver of BALB/c mice. (A) Type I collagen in periportal fibrosis; (B) type I collagen in isolated periovular granulomas; (C and E) presence of numerous small lamininpositive blood vessels in sections of pipestem fibrosis; $\mathrm{C}=$ single infection; $\mathrm{E}=$ repeated infections; $(\mathrm{D}$ and $\mathrm{F}$ ) idem, for isolated granulomas. Vessels present are much less numerous than in periportal fibrosis. Objective Plan-Apo, $10 \times(\mathrm{A})$ and $20 \times(\mathrm{B}-\mathrm{F})$.

when sections were marked for the presence of laminin, a component of the vessel wall, and examined by immunofluorescence (Fig. 2C-F). The percentage of laminin-delimited vessels measured by automated morphometry was much higher in mice with periportal fibrosis than in mice with isolated granulomas (Fig. 4). The presence of laminin-delimited vessels in periovular granulomas was much more prominent in animals submitted to repeated infections than those infected once.

Plastic casts obtained from the portal vasculature of uninfected Swiss Webster mice disclosed a vascular tree formed by regular dichotomous branching that progres- sively diminished in caliber down to fine, regular and delicate branches at the periphery (Fig. 5A and B). Casts obtained from the livers of mice presenting scattered isolated periovular granulomas were indistinguishable from those made from the livers of uninfected control mice. Plastic casts of the portal vasculature of mice with periportal fibrosis showed considerable diminution or amputation of the more delicate peripheral ramifications, which gave a "dried-tree" appearance to the cast (Fig. 5C and D). In addition, the larger branches of the portal veins (1st, 2nd and 3rd orders), which appeared smooth in the uninfected control liver, presented numer- 


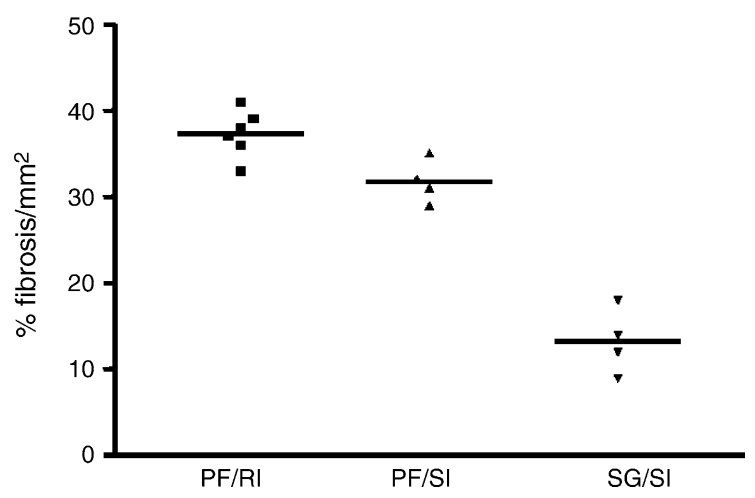

Fig. 3. Evaluation of hepatic fibrous tissue by morphometry. Picrosirius stained collagen in histological sections is expressed as a percentage of total fibrotic material examined in $12 \mathrm{~mm}^{2}$ for each animal. BALB/c mice infected with $S$. mansoni, sacrificed 20 weeks after cercarial exposure. PF/RI: periportal fibrosis from reinfection; PF/SI: periportal fibrosis from single infection; IG/SI: isolated granulomas from single infection.

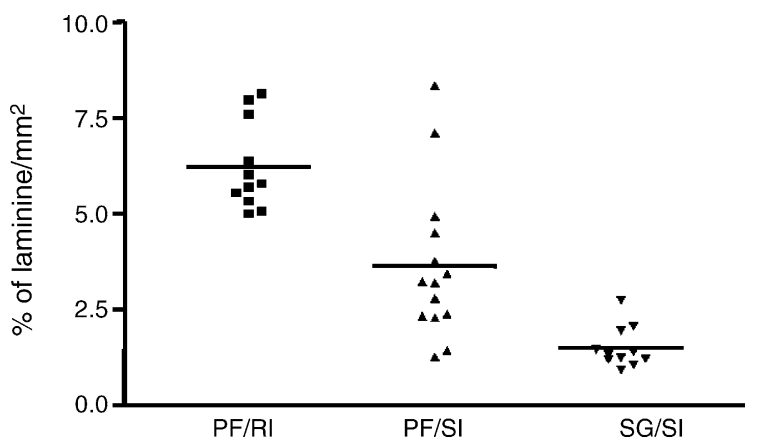

Fig. 4. Percentual evaluation of vascular tissue, as measured by indirect immunofluorescence of laminin-positive vascular basement membrane. Cryostat sections from BALB/c mouse liver taken 24-week $S$. mansoni infection. PF/RI: periportal fibrosis from reinfection; PF/SI: periportal fibrosis from single infection; IG/SI; isolated granulomas from single infection.

ous spikes, giving a "hairy" appearance to these branches (Fig. 5E). When observed under the dissecting microscope, the smallest vessels filled by the plastic revealed a series of abnormalities. These included sudden reduction of caliber (Fig. 5F-H), tortuosities, short-circuits (communications between neighboring vessels forming different geometric figures) (Fig. 5D), focal points of thinning and dilatation, sometimes alternating with one another, and formation of fine tufts, originating at terminal, partially obliterated vessels (Fig. 5F).

\section{Discussion}

This detailed morphological study of hepatic vascular changes that occur in the mouse model of schistosomiasis is a contribution to understanding the pathogenesis of the so-called hepatosplenic schistosomiasis. Vascular alterations caused by the disease in mice were similar to those described in humans with hepatosplenic disease (Andrade and Cheever, 1971), including distortions of the small and medium sized capillaries and appearance of small vessels sprouting from the largest portal veins. Andrade and Cheever (1971) presented evidences derived from studies with human material that embolization of large numbers of schistosome eggs during a critical stage of infection causes blockages of small peripheral pre-capillary vessels throughout the hepatic vascular system. These blockages probably result in intrahepatic congestion and hypertension that lead to vascular dilatation and allows the lodging of eggs in the periportal vessels, necessary steps in the development of periportal fibrosis.

In human hepatosplenic disease, vascular alterations in the liver are prominent and result in increased intrahepatic pressure, contributing to the severity of the illness (Andrade, 2004). There are abundance of dilated, thinwalled blood vessels within large fibrotic portal spaces, and occluded or absent portal veins in the peripheral spaces containing bile ducts and branches of the hepatic artery (Andrade and Cheever, 1971). These findings also point toward the fundamental importance of wormload in the pathogenesis of advanced schistosomiasis (Cheever, 1968). However, in prospective field studies in endemic areas individuals with the highest numbers of eggs eliminated in the feces were not necessarily at greater risk of developing periportal fibrosis (Coura and Conceição, 1981).

In the mouse model of schistosomiasis, we observed a prominence of blood vessels within periportal fibrosis in contrast to relatively avascular isolated granulomas. Liver sections of mice with periportal fibrosis had significantly more laminin-positive blood vessels than those of mice with isolated granulomas. Periportal fibrosis was not only characterized by an accumulation of periovular granulomas, but to the presence of richly vascularized granulomatous tissue. Chronic granulomatous inflammation may be considered an angiogenic-dependent process since one study demonstrates for the fist time that neutralizing antibody to vascular endothelial growth factor (VEGF) resulted in significant suppression of both angiogenesis and granuloma dry weight (Appleton et al., 1996). Schistosome eggs may stimulate angiogenesis directly through VEGF. In vitro, soluble egg antigens (SEA) up-regulate VEGF in human endothelial cells and promote endothelial cell proliferation and tube formation (Loeffler et al., 2002). Host immune response may also play a role, although in a separate study we did not observe differences in cytokine profiles or concentra- 

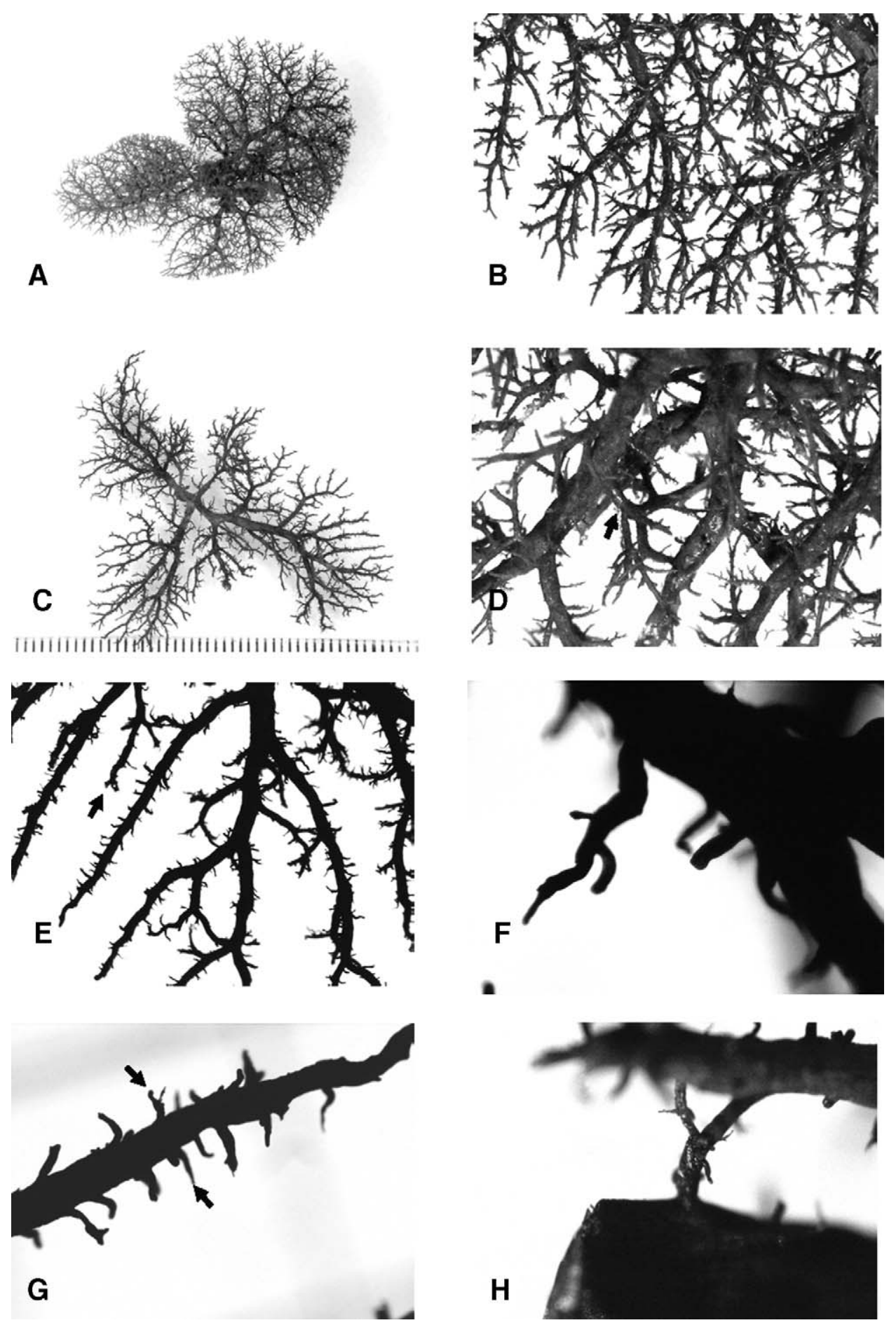

Fig. 5. Vynilite casts obtained from portal vasculature of mice infected with Schistosoma mansoni. (A) A panoramic view of a portal vein cast from a normal mouse; (B) a detailed view of a normal portal vein; $(\mathrm{C}-\mathrm{H})$ represent aspects of the portal vascular tree in cases of schistosomal hepatic pipestem fibrosis. (C) A panoramic view showing decreased number of fine peripheral branches; sprouting of fine, short, periportal collaterals coming from the main branches and distortion. Details are depicted in D: short-circuit (arrow); E: hairy appearance of collaterals. Arrows in E and $\mathrm{G}$ point to irregular branching, which also appear in $\mathrm{F}$ and $\mathrm{H}$ (sudden diminution of caliber). 
tions at a systemic level (Silva et al., 2004). Alternatively, formation of new blood vessels may be a compensatory response in the host to blockages of capillaries by schistosome eggs.

Although the deposition of large numbers of eggs may be an important determinant of vascular changes, we did not observe a consistent association between higher egg burden in the chronic phase of disease and pipestem fibrosis, in contrast to findings from a previous study in CBA/J mice (Henderson et al., 1993). Our failure to find a significant difference may be related not only to the small number of animals but to the variability in egg burden among individual animals in the same pathological group. BALB/c mice may also be particularly susceptible to the development of pipestem fibrosis, as the percentage of infected BALB/c mice that developed pipestem fibrosis $(>50 \%)$ was much higher than that reported in CBA/J mice (20\%, Henderson et al., 1993), and repeated infections did not appear to increase the proportion of infected mice that developed the pathology. We employed repeated infections to increase the number of mice that might develop periportal fibrosis, as repeated infections were associated with this pathology in a previous study with Swiss Webster mice (Santos et al., 2000) and in baboons (Farah et al., 2000). Repeated infections did increase the number of worms recovered in mice with periportal fibrosis in our study, and it is possible that this may have been associated with higher egg burden at different stages in infection. Timing and sequence of egg embolization rather than number of eggs alone may be crucial determinants of severe pathology (Andrade et al., 1997).

Because the pathology of periportal fibrosis in the mouse model appears very similar to that in humans, the determinants of severe disease are likely to be the same. Study of the mouse model permits investigation of the independent role of egg and host factors in the pathogenesis of disease. Understanding determinants of the development of periportal fibrosis in the mouse model may lead to new therapeutic strategies to prevent severe human disease.

\section{Acknowledgments}

This work was supported by Conselho Nacional de Desenvolvimento Científico e Tecnológico (CNPq) and Fundação Oswaldo Cruz (FIOCRUZ). We thank Sheilla Andrade de Oliveira, Rejane M.C. Menezes, Antônio Carlos S. Santos and Ana Cristina Gonzalez for technical support and Brendan Flannery for reviewing of the manuscript.

\section{References}

Andrade, Z.A., 1987. Pathogenesis of pipe-stem fibrosis of the liver (experimental observation on murine schistosomiasis). Mem. Inst. Oswaldo Cruz 82, 325-334.

Andrade, Z.A., 2004. Schistosomal hepatopathy. Mem. Inst. Oswaldo Cruz 99 (Suppl. 1), 51-57.

Andrade, Z.A., Cheever, A.W., 1993. Characterization of the murine model of schistosomal hepatic periportal fibrosis ('ipestem' fibrosis). Int. J. Exp. Pathol. 74, 195-202.

Andrade, Z.A., Cheever, A.W., 1971. Alterations of the intrahepatic vasculature in hapatoesplenic schistosomiasis mansoni. Am. J. Trop. Med. Hyg. 20, 425-432.

Andrade, Z.A., Silva, L.M., Souza, M.M., 1997. An experimental approach to the pathogenesis of "pipestem" fibrosis (Symmer's fibrosis of the liver). Mem. Inst. Oswaldo Cruz 92, 699-706.

Andrade, Z.A., Sadigursky, M., 1985. Um estudo comparativo das cepas Feira de Santana (Bahia) e Porto Rico do Schistosoma mansoni na infecção experimental do camundongo. Mem. Inst. Oswaldo Cruz 80, 37-40.

Appleton, I., Nicola, J.B., Willis, D., Colville-Nash, P.R., Alam, C., Brown, J.R., Willoughby, D.A., 1996. The role of vascular endothelial growth factor in a murine chronic granulomatous tissue air pouch model of angiogenesis. J. Pathol. 180, 90-94.

Bergman, I., Loxley, R., 1963. Two improved and simplified methods for the spectrophotometric determination of hydroxyproline. Anal. Chem. 35, 1961-1965.

Bina, J.C., Prata, A., 1984. Evolução natural da esquistossomose em uma área endêmica. Aspectos peculiares da infecção por Schistosoma mansoni. Publicações do Centro de Estudos de Doenças Regionais Endêmicas (CEDRE), Salvador, BA, pp. 13-14.

Cheever, A.W., 1968. A quantitative post-mortem study of schistosomiasis mansoni in man. Am. J. Trop. Med. Hyg. 17, 38-64.

Cheever, A.W., 1970. Relative resistance of the eggs of human schistosomes to digestion in potassium hydroxide. Bull. WHO 43, 601-603.

Coura, J.R., Conceição, M.J., 1981. Correlação entre carga parasitária do $S$. mansoni e gravidade das formas clínicas em uma comunidade rural de Minas Gerai. Rev. Soc. Bras. Med. Trop. 14, 93-97.

Duvall, R.H., Dewitt, W.B., 1967. An improved perfusion technique for recovering adult schistosomes from laboratory animals. Am. J. Trop. Med. Hyg. 16, 483-486.

Farah, I.O., Mola, P.W., Kariuki, T.M., Nyindo, M., Blanton, R.E., King, C.L., 2000. Repeated exposure induces periportal fibrosis in Schistosoma mansoni-infected baboons: role of TGF-beta and IL-4. J. Immunol. 164, 5337-5343.

Henderson, G.S., Nix, N.A., Montesano, M.A., Gold, D., Freeman G.L.JJr., Mccurley, T.L., Colley, D.G., 1993. Two distinct pathological syndromes in male CBA/J inbred mice with chronic Schistosoma mansoni infections. Am. J. Pathol. 142, 703-714.

Junqueira, L.C.U., Bignolas, G., Brentani, R., 1979. Picrosirius staining plus polarization microscopy, a specific method for collagen detection in tissue sections. Histochem. J. 11, 447-455.

Loeffler, D.A., Lundy, S.K., Shing, K.P., Gerard, H.C., Hudson, A.P., Boros, D.L., 2002. Soluble egg antigens from Schistosoma mansoni induce angiogenesis-related processes by up-regulating vascular endothelial growth factor in human endothelial cells. J. Infect. Dis. $185,1650-1656$.

Prata, A., 1991. Fatores determinantes das formas anátomo-clínicas e evolução da esquistossomose. In: Castro, F.P., Rocha, P.R.S., Cunha, A.S. (Eds.), Tópicos em Gastoenterologia. MEDSI-Editora Médica e Científica Ltda., Rio de Janeiro, pp. 3-12. 
Santos, A.B.A., Souza, M.M., Andrade, Z.A., 2000. Reinfecções e desenvolvimento da fibrose periportal esquistossomótica no modelo murino. Rev. Soc. Bras. Med. Trop. 33, 197-200.

Silva, L.M., Oliveria, S.A., Ribeiro-dos-Santos, R., Andrade, Z.A., Soares, M.B., 2004. Comparison of immune responses of Schistosoma mansoni-infected mice with distinct chronic forms of the disease. Acta Trop. 91, 189-196.
Symmers, W.StC., 1904. Note on a new form of liver cirrhosis due to the presence of the ova of Bilharzia haematobia. J. Pathol. Bacteriol. 9, 237-239.

Warren, K.S., 1966. The pathogenesis of "clay-pipe stem cirrhosis" in mice with chronic schistosomiasis mansoni, with a note on the longevity of the schistosomes. Am. J. Pathol. 49, 477489 . 